\title{
ARTICLE \\ Quality of Papers Stems from Authors and Quality of Teaching Stems from Professors
}

\section{Fausto Galetto*}

Industrial Quality Management, Politecnico di Torino, Turin, Italy

\begin{tabular}{|c|c|}
\hline ARTICLE INFO & ABSTRACT \\
\hline Article history & \multirow{9}{*}{$\begin{array}{l}\text { On the web it is very frequently found that good papers are published only } \\
\text { in "Peer Reviewed Trusted Journals (PRTJ)", while low quality papers are } \\
\text { published in the "Predatory Publishing Journals". Here we show that this is } \\
\text { not true, because the quality of papers depends on the quality of the authors } \\
\text { in the same manner that quality of teaching depends on the quality of pro- } \\
\text { fessors. Since generally the authors are professors it is important to see the } \\
\text { two sides of the "publishing medal": authors and professors. We will use } \\
\text { the SPQR Principle [«Semper Paratus ad Qualitatem et Rationem (Always } \\
\text { Ready for Quality and Rationality)»] as the way to analyse papers, books } \\
\text { and teaching; it seems that very few people have taken care of Quality of } \\
\text { Methods (Deming, Juran, Gell-Mann, Shewhart, Einstein, Galilei). The } \\
\text { cases analysed here are from PRT Journals and teaching documents. }\end{array}$} \\
\hline Received: 14 December 2020 & \\
\hline Accepted: 30 December 2020 & \\
\hline Published Online: 31 March 2021 & \\
\hline Keywords: & \\
\hline SPQR & \\
\hline Quality of methods & \\
\hline Design of experiments & \\
\hline Quality education & \\
\hline
\end{tabular}

Peer review

Open access

Non-open access

Methods for quality

Rational manager

Quality tetralogy

Intellectual honesty

\section{Introduction}

There are many Open Access Journals which publish papers and ask a fee for that [named APC (Article Processing Charge) or a similar acronym]. They are classified, in Wikipedia, as "Predatory publishing".

There are several scholars thinking that a proof of documents Quality depends on their citations; this author saw that the BAD attitude is well diffused: those researchers do not consider that citations depend many times on the

readers that are unable to evaluate the scientificity of the ideas given in the papers ${ }^{[39-116]}$ because they do not analyse the data Scientifically and are unable to decide if the methods provided are Scientific or not.

Unfortunately, Universities generate a great need of publishing papers, because they ask for publications to become professors. This author had the opportunity to analyse many of those papers and many times when he asked to the applicants (for professorship) "Why did you write such a statement..." he received the reply either "My

*Corresponding Author:

Fausto Galetto,

Industrial Quality Management, Politecnico di Torino, Turin, Italy; Email:fausto.galetto@gmail.com 
colleague wrote that,,," or "I found it in Wikipedia" or "I read it in that book...": in spite of their incompetence, they were promoted to become professors!

See this from A. Einstein thinking: «An Academic career poses a person in an embarrassing position, asking him to produce a great number of scientific publications...».

This is a concept shared by this author ${ }^{[99]}$, because he saw many researchers doing that, without taking care of Quality of papers. ${ }^{[83-101]}$ The author met several professors who wrote wrong papers and were teaching wrong ideas to their students, using wrong books. ${ }^{[10-24]}$

There is a vast criticism about Open Access Journals (OAJ) on the web: since they ask fees for publishing papers OAJ are considered as "means for tricking people"; see for example, for SPG, in ${ }^{[1,2]}$ "Science Publishing Group is not read by scientists..."

Actually, author's opinion (based on his long experience) is that the quality of papers is not related to the fee, asked by the OAP; on the contrary, it depends mainly on the authors low quality and on the Peer Reviewers; it is the same for "trusted magazines and journals ${ }^{\prime \prime}{ }^{183-127]}$.

To avoid that, this author invented the SPQR Principle [«Semper Paratus ad Qualitatem et Rationem ("Always Ready for Quality and Rationality")»] as the way to analyse both books and papers ${ }^{[112]}$; only that very few people have been considering carefully Quality of the Methods: e. g., Deming, Juran, Gell-Mann, Shewhart ${ }^{[3-8]}$. The author never met somebody else who did that... As a consequence, professors, researcher, managers, scholars and students have been learning wrong ideas, in the Quality field: there is worldwide used book with many wrong concepts \{e.g., D. C. Montgomery falls in contradiction! He spreads wrong concept on Quality $\left.{ }^{[9,10]}\right\}$. Is an OAP the publisher Wiley \& Sons? Obviously not! See the Formula 1 Race in Bahrain (December 6 2020): Bottas 4 pt., Russell 3 pt., Vettel 0 pt., Leclerc 0 pt.: Mercedes had lower "quality" than Ferrari!!! A similar case happened in Abu Dhabi; Bottas 18 pt., Hamilton 15 pt., Vettel 0 pt., Leclerc 0 pt.: Mercedes had again lower "quality" than Ferrari!!!

In this paper we shall use various ideas that the readers can find in the paper ${ }^{[99]}$. It is a paper from an Open Access Journal; is it not read? We do not know. If really it is not read it is important to repeat some ideas you can find there.

We will cite several times the QEG of a University; quite a few professors in QEG still suggest the Montgomery books to students; bad idea: see the case analysed in ${ }^{[112]}$ which has various problems ${ }^{[11,12]}$. In the web (www. qualityengineering.polito.it) you can find the hyped ideas of QEG about "their Quality”. Fantastic... See Ref.

The last paper you can find there is ${ }^{[128]}$ (M. Galetto et al.). Surely, that journal is not OAP! The paper shows some methods for the analysis of experimental and optimisation of a process for Selective Laser Melting. There one find the Design of Experiment (DoE) and analysis about which the authors consider very "effective... ${ }^{[128]}$ ".

Here are the data.

Table 1. [full design $3^{3}$; measured Hardness is the response]

\begin{tabular}{|c|c|c|c|c|c|r|c|c|c|}
\hline Run & $P(\mathrm{~W})$ & $V(\mathrm{~mm} / \mathrm{s})$ & $h d(\mathrm{~mm})$ & $\psi(\mathrm{J} / \mathrm{mm} 3)$ & Hardness(HB) & Test no. & level & level & level \\
\hline 1 & 340 & 900 & 0.11 & 114.48 & 85.7 & 1 & 1 & 1 & 1 \\
\hline 2 & 340 & 900 & 0.15 & 83.95 & 90.3 & 2 & 1 & 1 & 2 \\
\hline 3 & 340 & 900 & 0.19 & 66.28 & 103.7 & 3 & 1 & 1 & 3 \\
\hline 4 & 340 & 1300 & 0.11 & 79.25 & 96.7 & 4 & 1 & 2 & 1 \\
\hline 5 & 340 & 1300 & 0.15 & 58.12 & 115.0 & 5 & 1 & 2 & 2 \\
\hline 6 & 340 & 1300 & 0.19 & 45.88 & 121.0 & 6 & 1 & 2 & 3 \\
\hline 7 & 340 & 1700 & 0.11 & 60.61 & 120.3 & 7 & 1 & 3 & 1 \\
\hline 8 & 340 & 1700 & 0.15 & 44.44 & 118.7 & 8 & 1 & 3 & 2 \\
\hline 9 & 340 & 1700 & 0.19 & 35.09 & 119.7 & 9 & 1 & 3 & 3 \\
\hline 10 & 355 & 900 & 0.11 & 119.53 & 76.0 & 10 & 2 & 1 & 1 \\
\hline 11 & 355 & 900 & 0.15 & 87.65 & 87.7 & 11 & 2 & 1 & 2 \\
\hline 12 & 355 & 900 & 0.19 & 69.20 & 99.7 & 12 & 2 & 1 & 3 \\
\hline 13 & 355 & 1300 & 0.11 & 82.75 & 108.0 & 13 & 2 & 2 & 1 \\
\hline 14 & 355 & 1300 & 0.15 & 60.68 & 116.3 & 14 & 2 & 2 & 2 \\
\hline 15 & 355 & 1300 & 0.19 & 47.91 & 119.7 & 15 & 2 & 2 & 3 \\
\hline 16 & 355 & 1700 & 0.11 & 63.28 & 114.7 & 16 & 2 & 3 & 1 \\
\hline 17 & 355 & 1700 & 0.15 & 46.41 & 118.7 & 17 & 2 & 3 & 2 \\
\hline 18 & 355 & 1700 & 0.19 & 36.64 & 115.3 & 18 & 2 & 3 & 3 \\
\hline 19 & 370 & 900 & 0.11 & 124.58 & 78.7 & 19 & 3 & 1 & 1 \\
\hline 20 & 370 & 900 & 0.15 & 91.36 & 87.3 & 20 & 3 & 1 & 2 \\
\hline 21 & 370 & 900 & 0.19 & 72.12 & 84.7 & 21 & 3 & 1 & 3 \\
\hline 22 & 370 & 1300 & 0.11 & 86.25 & 100.3 & 22 & 3 & 2 & 1 \\
\hline 23 & 370 & 1300 & 0.15 & 63.25 & 110.3 & 23 & 3 & 2 & 2 \\
\hline 24 & 370 & 1300 & 0.19 & 49.93 & 118.3 & 24 & 3 & 2 & 3 \\
\hline 25 & 370 & 1700 & 0.11 & 65.95 & 120.3 & 25 & 3 & 3 & 1 \\
\hline 26 & 370 & 1700 & 0.15 & 48.37 & 116.3 & 26 & 3 & 3 & 2 \\
\hline 27 & 370 & 1700 & 0.19 & 38.18 & 116.3 & 27 & 3 & 3 & 3 \\
\hline
\end{tabular}

And here, there is the optimum they find....

\begin{tabular}{|c|c|c|c|c|c|}
\hline \multicolumn{4}{|c|}{ Control factors } & \multicolumn{2}{|c|}{ Response predicted value } \\
\hline$P(\mathrm{~W})$ & $v(\mathrm{~mm} / \mathrm{s})$ & $h_{d}(\mathrm{~mm})$ & $\psi\left(\mathrm{J} / \mathrm{mm}^{3}\right)$ & $\begin{array}{l}\text { Response } \\
\text { value } \\
(\mathrm{HB})\end{array}$ & $\begin{array}{l}\text { Response 95\% } \\
\text { CI (HB) }\end{array}$ \\
\hline 340 & 1538.4 & 0.19 & 38.78 & 122.45 & $(118.08 ; 126.83$ \\
\hline
\end{tabular}

Response optimisation and predicted value

$$
\text { Excerpt 1. (from }{ }^{[128]} \text { ) }
$$

Any intelligent student can easily find that the optimum is already in Table 1, without any use of Minitab!

We will see later other findings of QEG.

QEG team thinks that citations are very important for measuring quality of papers.... Actually there are various ideas about Bibliometrics in the paper ${ }^{[97]}$ The interested reader can see there.

In the paper ${ }^{[112]}$ we analysed a case taken from a QEG book ${ }^{[32]}$ (published by Springer-Verlag which apparentently is not an OAP!!!); it is an application of DOE, as the one in Table 1 (where there are the data...). There ${ }^{[32]}$ we did not have the data; that was a situation where several times a reader can find himself: the authors of the documents provide their conclusions and the reader has not any possibility of verifying them: "Take it or leave it"! It is the same in ${ }^{[33]}$, another NOAP! 
Other wrong documents are ${ }^{[9,10,11,--, 29,30,31]}$ : they are not published by OAP, asking the fee. There any intelligent reader can see that, for OAP documents, the Quality depends on the authors.... and on the "Peer Reviewers"; you can find many ideas in the papers ${ }^{[111,112]}$. See also Figure 2.

Readers do apply SPQR, in order not to be cheated; if you use your own intelligence and that Principle you understand clearly the issue (remember the Quality Tetralogy: every Scholar must remember Figure 1).

The present paper (as many others of this author, in References) is written for Managers, for Students (who will become Managers), for Young Researchers (who will become Scientific Researchers), for Scholars (who want to learn good ideas Scientifically), and to Professors.

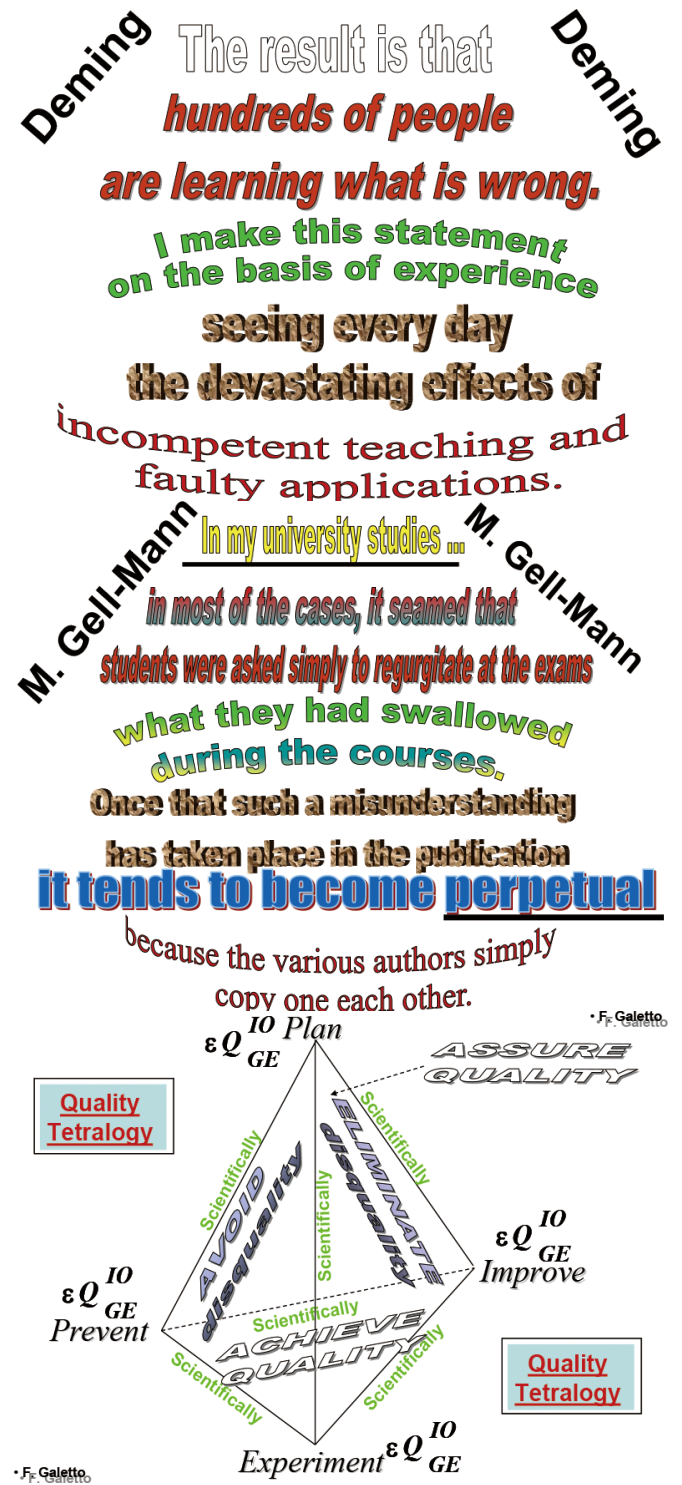

Figure 1. Statements from Deming, Gell-Mann, Galetto ideas.

As appreciated by J. Juran who, at the 1989 EOQC
Conference in Vienna, highlighted the content of the paper

${ }^{[50]}$ about the importance of the Quality of the methods for making quality: the paper shows the only good methods are crucial for suitable decision taking.

Since the data are unfortunately always variable we must take into account all the uncertainties, because they have consequences on our decisions: we face "decision-making under uncertainty".

In many cases, a reader is confronted with the fact that he does not have the data; therefore he cannot analyse the authors' conclusions; this is a very bad situation.

Other times it is very easy to find the errors; see the following wrong attached statement taken from a course on Quality Management, where QEG members suggest Montgomery books to students ${ }^{[! ! !]}$

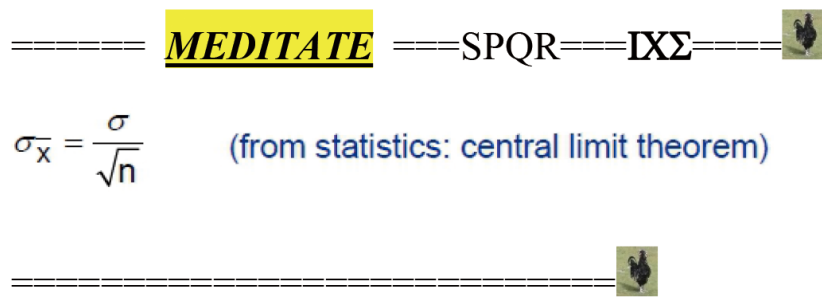

Any good student knows that the previous formula holds for any distribution and any sample size $n$ : the Central Limit Theorem does not have any importance for that, $\underline{B U T}$ QEG professors do not know that!!!!!!! Remember: that formula holds for any distribution and any sample size $n$.

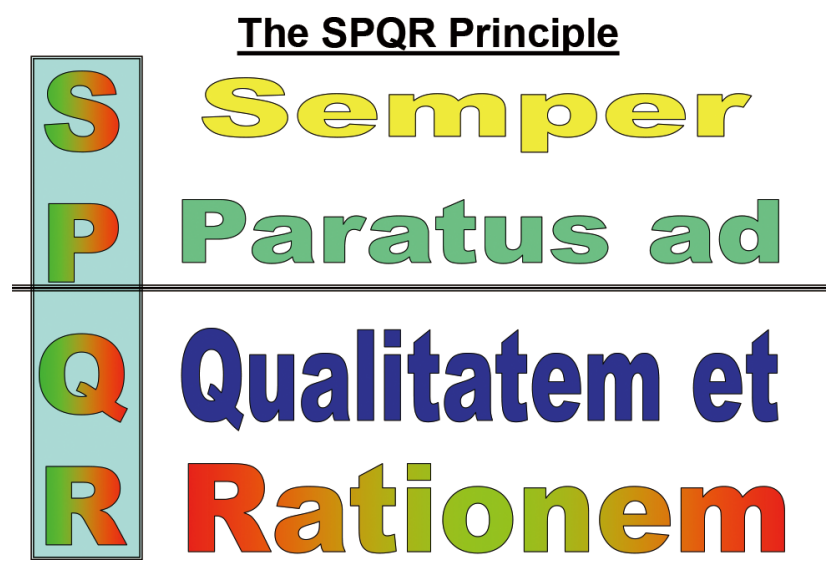

Figure 2. The SPQR Principle.

Several F. Galetto documents ${ }^{\text {[from } 37 \text { to } 112]}$ proved and are proving that the negative considerations on the OAP ${ }^{[1,2]}$ are valid also for other publishers: see the references and Academia.edu and Research Gate.

Remember J. Juran ${ }^{[50]}$ for Decision-Making.

\section{A first Case of a Non-OAP Paper}

We consider here the content of a paper, published by NOAP, that has the same problems of the OAP: the cause 
is the authors' and Referees' incompetence. It is the first of two papers both related to the QEG Turin Politecnico... F. Galetto did not have any success in inviting them to act scientifically, many times, in their work!

The members of QEG think that papers published in Trusted Journals are good, by definition: several times that is untrue.

We consider first the paper ${ }^{[128]}$. The author uses in the paper the data (nc stands for number of non-conformity, while $\mathrm{p}$ is the proportion) from the Montgomery book, the book suggested [as done by the QEG] to his students; $T Q M$ is a NOAP,obviously.

${ }^{[126]}$ is another paper of him...

Table 2. taken from ${ }^{[128]}$

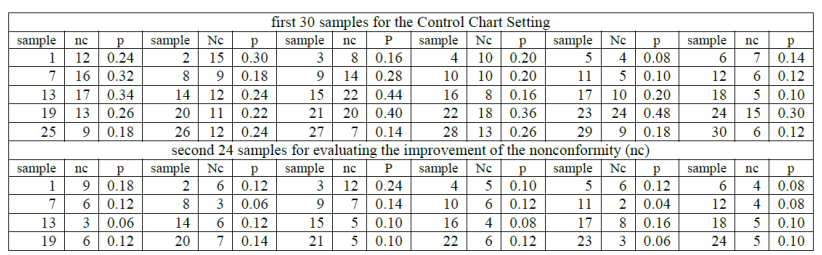

The following Figure 3, taken from Montgomery book, shows the Control Chart, when all the samples are considered.

The author puts $\mathrm{x}=1 / \mathrm{t}$ and computes the means $\overline{t_{1}}$ and $\overline{t_{2}}$ of the time lengths related to the $1^{\text {st }} 30$ samples and the $2^{\text {nd }} 24$ samples; he then interpolates the proportion $\mathrm{p}$ of the nonconformities $\overline{p_{1}}$ (mean of the $1^{\text {st }} 30$ samples) and $\overline{p_{2}}$ (mean of the $2^{\text {nd }} 24$ samples) both concentrated, respectively, at $\overline{t_{1}}$ and $\overline{t_{2}}$ !!!! There are only two values for the nonconformity proportion $\mathrm{p}$ with only two time means: from these two points one can easily find the estimates of "a" and "c".

The interpolation is made with a curve having equation $\mathrm{y}=\mathrm{c}+\mathrm{ax}$; a and $\mathrm{c}$ are estimated by

$$
\hat{a}=\frac{\overline{p_{1}}-\overline{p_{2}}}{1 / \overline{t_{1}}-1 / \overline{t_{2}}} \text { and } \hat{c}=\overline{/ p_{1}}-a \overline{t_{1}}
$$

with variance

$$
\sigma_{a}^{2}=\left[\overline{t_{1} t_{2}} /\left(\overline{t_{2}}-\overline{t_{1}}\right)\right]^{2}\left(\sigma_{p 1}^{2}+\sigma_{p 2}^{2}\right)
$$

and

$\left.\sigma_{c}^{2}=\left[\overline{t_{2}} /\left(\overline{t_{2}}-\overline{t_{1}}\right)\right]^{2} \sigma_{p 1}^{2}+\left[\overline{t_{1}} /\left(\overline{t_{2}}-\overline{t_{1}}\right)\right]^{2} \sigma_{p 2}^{2}\right)$

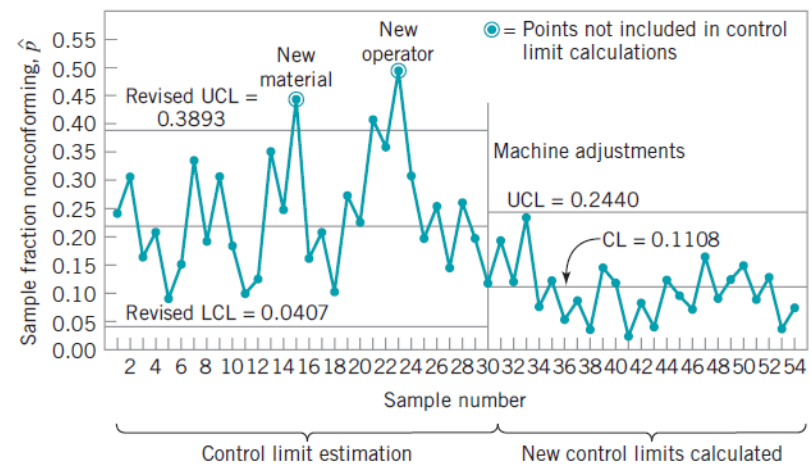

Figure 3. The Example of a Control Chart from Montgomery book

$\overline{p_{1}}$ is the mean of the $1^{\text {st }} 30$ samples and $\overline{p_{2}}$ is the mean of the $2^{\text {nd }} 24$ samples!!!! They are the only two values for the nonconformity proportion $\mathrm{p}$ with only two time means: from these two points one can easily find the estimates of "a" and "c". With 30 values $\mathrm{p}_{\mathrm{i}}$ and the other $24 \mathrm{p}$ we have two "estimators" $\bar{P}_{1}$ and $\overline{P_{2}}$ (Random Variables) for which we can "accept" the Central Limit Theorem: they follows the normal distribution and then we can compute the Confidence Intervals (CI) ${ }^{[99, a]}$.

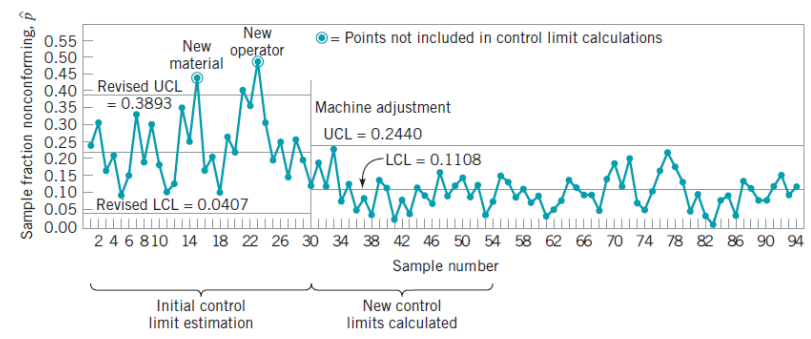

Figure 4. The Example of a Control Chart from Montgomery book

The QEG author did not compute the CI! Since, actually, the value 0 belongs to both the CI; therefore, anybody, with the two previous, derives that the parameters significantly different from $0 ! ! !$

The QEG author did not realise that the asymptotic defectiveness derived from those formula is nonsense: Look at the Figure 4, with 40 more samples, taken from the Montgomery book: it shows the nonsense!!!

Do you see how much wrong was the QEG professor?

The referee of the paper did not find the error, as well, because he did not used the SPQR!

Remember Juran at Vienna EOQC Conference!

Since $T Q M$ is a trusted journal is evident that Quality of papers stems from the authors and does not stem from the publishers.

Therefore it is not true that only "Predatory publishing,..." (from Wikipedia), provide their readers with poor quality papers!!! 


\section{A second Case of a Non OAP Paper}

QEG members have been very active on Process Control; they invented in 1998 the "Qualitometro I method" and in1999-2000 the "Qualitometro II" and in 2005 QEG members invented the "Qualitometro III method" in the papers related to ${ }^{[129]}$.

We cannot give here all the ideas of the QEG members; the interested readers can see various author's papers ${ }^{[73-79,}$ 86-95, 87, 99-101].

We consider very interesting to draw the readers' attention on the fact that some Turin Politecnico students, L. Perri (2002), E. Mori (2006) and J. Baucino (2008) found the drawbacks of fuzzy sets in control charts. Using the Scientific Approach they could find that the wrong "control Charts" provide at least $20 \%$ out of control events for random data "uniformly distributed" on the scale points: such data "uniformly distributed" must be "in control" by definition!!! [73-79, 86-95, 87, 99-101]

Clearly, fuzzy sets in control charts are wrong in the way they are used in applications to Quality. [see References]

It is important to mention that those wrong ideas were copied [see Figure 1] from ${ }^{[130]}$.

Those trusted journals are surely NOAP.

Nevertheless they put out wrong papers.

It is natural that those (authors) professors teach wrong ideas to their students. ${ }^{[126]}$

The findings of F. Galetto are opposite to what it can be found in the web about OAJ as "means for tricking people" (asking fees for publishing papers).

It is very clear that the bad quality happens for "well reputed and trusted magazines and journals", as well. See [from 85 to 95,126 ]

\section{A third case of a NOAP paper}

In the introduction we mentioned a DoE about which the QEG authors (M. Galetto, et al.) hyped their "effective" methods; it is found in the paper ${ }^{[127]}$. Surely, that journal is not OAP! The data are in Table 1: it is a full design $3^{3}$ (3 factors at 3 levels each); the response is the Hardness. The QEG authors, using Minitab 17, make all the computations and find the optimum setting in the Excerpt 1 .

Their optimum response is Hardness $=122.45 \mathrm{HB}$; the authors compute the $95 \%$ Confidence Interval of the opti-

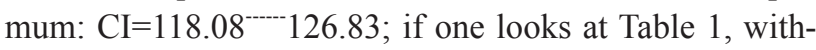
out any use of Minitab, he can see the maximum 121.0, at run 6.

\begin{tabular}{|c|c|c|c|c|c|r|c|c|c|}
\hline Run & $P(\mathrm{~W})$ & $V(\mathbf{m m} / \mathrm{s})$ & $h d(\mathbf{m m})$ & $\psi(\mathrm{J} / \mathrm{mm} 3)$ & Hardness(HB) & Test no. & Level & level & level \\
\hline $\mathbf{6}$ & $\mathbf{3 4 0}$ & $\mathbf{1 3 0 0}$ & $\mathbf{0 . 1 9}$ & $\mathbf{4 5 . 8 8}$ & $\mathbf{1 2 1 . 0}$ & $\mathbf{6}$ & $\mathbf{1}$ & $\mathbf{2}$ & $\mathbf{3}$ \\
\hline 7 & 340 & 1700 & 0.11 & 60.61 & 120.3 & 7 & 1 & 3 & 1 \\
\hline 8 & 340 & 1700 & 0.15 & 44.44 & 118.7 & 8 & 1 & 3 & 2 \\
\hline 9 & 340 & 1700 & 0.19 & 35.09 & 119.7 & 9 & 1 & 3 & 3 \\
\hline 15 & 355 & 1300 & 0.19 & 47.91 & 119.7 & 15 & 2 & 2 & 3 \\
\hline 17 & 355 & 1700 & 0.15 & 46.41 & 118.7 & 17 & 2 & 3 & 2 \\
\hline 24 & 370 & 1300 & 0.19 & 49.93 & 118.3 & 24 & 3 & 2 & 3 \\
\hline 25 & 370 & 1700 & 0.11 & 65.95 & 120.3 & 25 & 3 & 3 & 1 \\
\hline
\end{tabular}

We do not know if the runs were carried out in the standard order or in random order; we can analyse the data "in a Control Chart way" obtaining the Figure 5

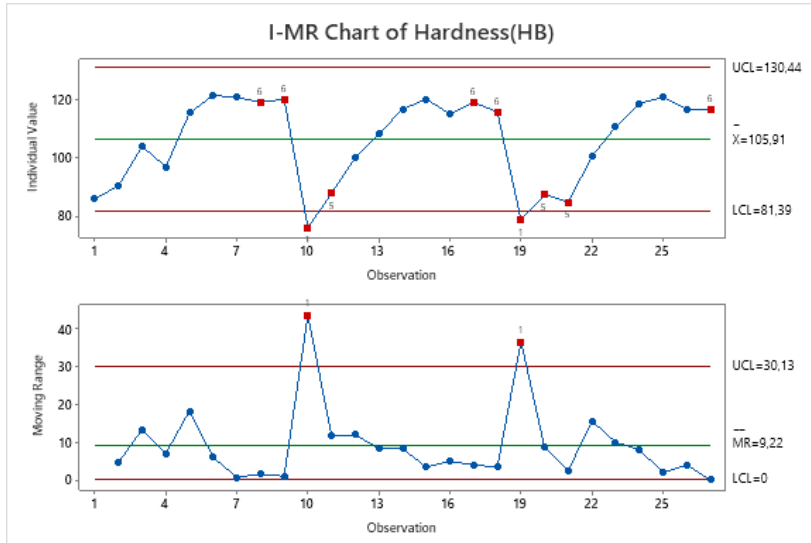

Figure 5. Analysis of the data of Table 1 (Control Chart)

The "Control Chart" (assuming that the data were Normally Distributed, as done by the paper authors) shows pictorially the runs (that you see in the previous table) were the response is near the optimum.

If the problem were to find the optimum, anybody could find it only by looking at the maximum of Hardness, because the Design is a Full Factorial.

On the contrary, the authors were forced to assume that the data were Normally Distributed, before making any calculation.

From Figure 6, we see clearly that the Distribution is not Normal.

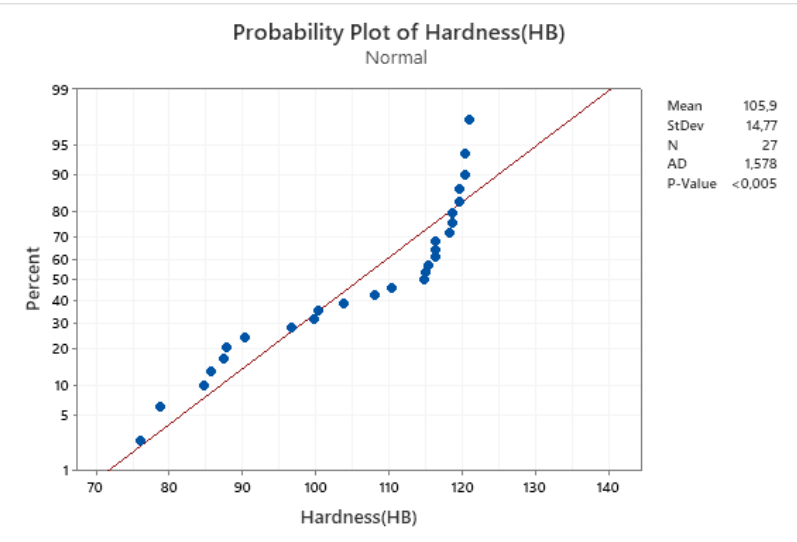

Figure 6. Distribution of Hardness (data in table 1): it is not Normal

Therefore, one cannot apply the Least Square Method 
(either of ANOVA, or of RSM).

In spite of that, the paper authors found the function

$H B=\beta_{0}+\beta_{1} \cdot P+\beta_{2} \cdot v+\beta_{3} \cdot h_{d}+\beta_{4} \cdot v^{2}+\beta_{5} \cdot v \cdot h_{d}$

Excerpt 2 (from ${ }^{[127]}$ )

From that, they found the optimum 6 mod in the following table.

\begin{tabular}{|c|c|c|c|c|c|c|c|c|c}
\hline Run & $P(\mathrm{~W})$ & $V(\mathrm{~mm} / \mathrm{s})$ & $h d(\mathrm{~mm})$ & $\psi(\mathrm{J} / \mathrm{mm} 3)$ & Hardness $(\mathrm{HB})$ & Test no. & Level & level & level \\
\hline $\mathbf{6}$ & $\mathbf{3 4 0}$ & $\mathbf{1 3 0 0}$ & $\mathbf{0 . 1 9}$ & $\mathbf{4 5 . 8 8}$ & $\mathbf{1 2 1 . 0}$ & $\mathbf{6}$ & $\mathbf{1}$ & $\mathbf{2}$ & $\mathbf{3}$ \\
\hline 6mod & $\mathbf{3 4 0}$ & $\mathbf{1 5 3 8 . 4}$ & $\mathbf{0 . 1 9}$ & $\mathbf{3 8 . 7 8}$ & $\mathbf{1 2 2 . 4 5}$ & & & & \\
\hline
\end{tabular}

Notice that $\mathrm{P}$ and hd are at the same level; only $\mathrm{V}$ is "almost in the middle" between 1300 and 1700 .

From the analysis it turns out that that Hardness values 121.0 and 122.45 are NOT significantly different with $\alpha=5 \%$.

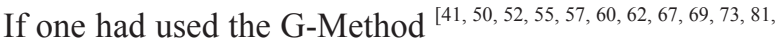
85, 94-95, 99-101, 104, 109-112] and not Minitab, he would have found a better equation (using the same symbols of Excerpt 1...) $H B=\beta_{0}+\beta_{1} P+\beta_{2} v+\beta_{3} h_{d}+\beta_{4} v^{2}+\beta_{5} v h_{d}+\beta_{6} P v+\beta_{7} P v^{2}+\beta_{8} P^{2} v^{2}+\beta_{9} P h_{d}+\beta_{10} v h_{d}$

This equation is also confirmed by the interaction plot of Figure 7

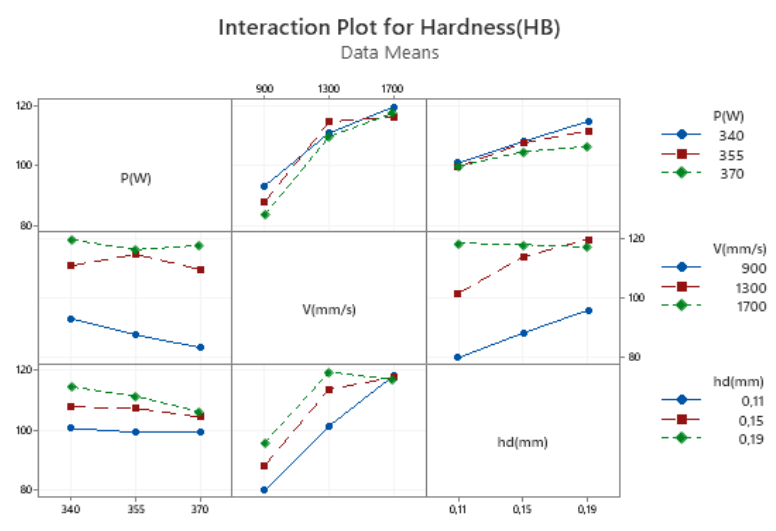

Figure 7. Interactions between the factors (data in Table 1): Normal distribution NOT needed

Again we see that a NOAP journal "International Journal of Precision Engineering and Manufacturing" (fee not asked for publication) publishes papers with some problems: methods used that did not respect the assumption of the methods, conclusions drawn that did not consider the Confidence Intervals (CI), regression equations with cut coefficients, interactions not completely considered, ...; to act correctly those authors should have transformed the data to get "normality" or to find the Theory for NONnormal data.

Transforming the data of Table 1 into "Normally distributed data" (using the Johnson transformation), we can find the following chart: it is clearly seen that run 6 pro- vides the optimum setting (maximum response).
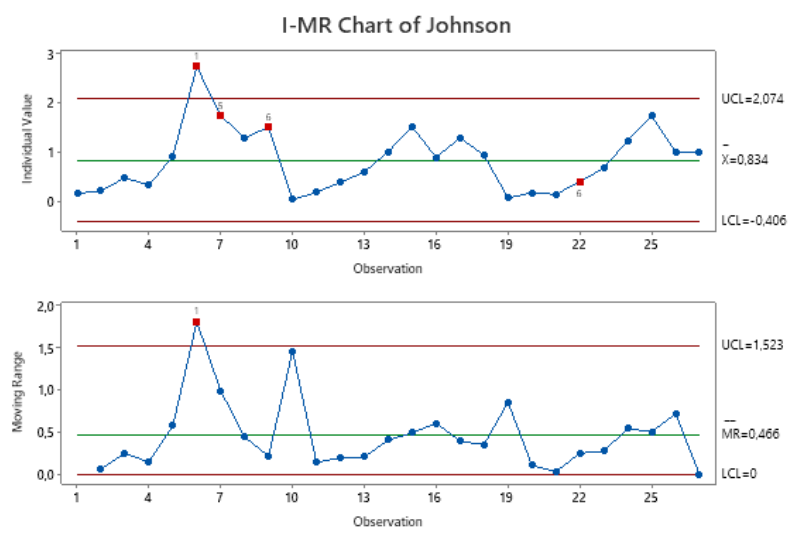

Figure 8. Control Chart versus Runs: data transformed to Normal

\section{Control Charts with Exponentially Distrib- uted Data. MINITAB Wrong}

This author posted a question at site iSixSigma ${ }^{[113]}$ related to control charts: "control-charts-non-normal-distribution" asking for the "solution to two cases shown in a file".

Both were related to the problem of finding if the process is In Control (IC) or Out Of Control (OOC); the solution of the two cases depend on the distribution of the data. the first case can be found in the book of D. C. Montgomery, with data following the exponential distribution; ; Montgomery dealt it wrongly in all the editions of the book, after 1996.

His solution was wrong and still it is because he, with his methods, decides that the process IC, when actually it is OOC; the "experts" of site iSixSigma ${ }^{[13]}$ did not wanted to consider the truth (process Out Of Control) and challenged F. Galetto about writing a "good" paper to be "Peer Reviewed" and, only later, to be published in a "Well-known Journal". They did not believe the authors "scientific" ideas.

One participant at the discussion suggested the Minitab Software for analysing the data as "rare events" (according to him, T Charts were the good method to use).

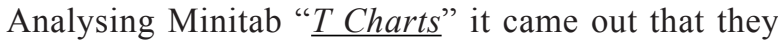
were wrong.

At that stage, the author posted the information and emailed Minitab Inc. asking the theory of the wrong $\mathrm{T}$ Charts.

The author and Minitab exchanged several e-mails; the conclusion (for MINITAB19) was:

\section{From MINITAB:}

1. There was no free technical support for the theory of 


\section{the T charts,}

2. and they suggested me to consult a statistician

3. or to pay their Statistical Consulting service. (pay for a Wrong Method!!!)

The author replied that they had to keep their WRONG method, and to sell it, WITH ERRORS, to their Customers, let them to "TAKE WRONG DECISIONS".

Notice that Minitab20 has still the same problem: December 16 2020. See Figure 1.

F. Galetto was asked to read the paper of Joel Smith ${ }^{[114]}$.

Unfortunately, Control Limits provided by that "Peer Reviewed" paper, whose authors worked with Minitab Inc. are wrong.

The truth was rejected at iSixSigma ${ }^{[113]}$ post.

A new challenge arouse for the author.

To understand the matter, the reader is asked to get the basics about the Shewhart Control Charts and the Individual Control Charts ${ }^{[7,8]}$ and the Reliability Integral Theory (RIT) ${ }^{[102-108]}$ which allows to find the correct control limits of charts with exponentially distributed data; RIT was devised by the author in 1975 (45 years ago) well before the $\mathrm{T}$ Charts invention.

Incompetent professionals diffuse wrong ideas: Ignorance is flooding and overflowing!!!

We consider the Example 7.6 in the Montgomery book $7^{\text {th }}$ edition. The data (named lifetime), in the Table 3, follow the exponential distribution; (we used Minitab 19 to show the problems):

Table 3. Lifetimes [from the Montgomery book]

\begin{tabular}{|c|c|c|c|c|c|c|c|c|c|}
\hline 286 & 948 & 536 & 124 & 816 & 729 & 4 & 143 & 431 & 8 \\
\hline 2837 & 596 & 81 & 227 & 603 & 492 & 1199 & 1214 & 2831 & 96 \\
\hline
\end{tabular}

Since the data are few (20) and exponentially distributed one cannot use the usual formulae based on the Normal distribution. If one would [wrongly] do use formulae he would find the following Figure 9.

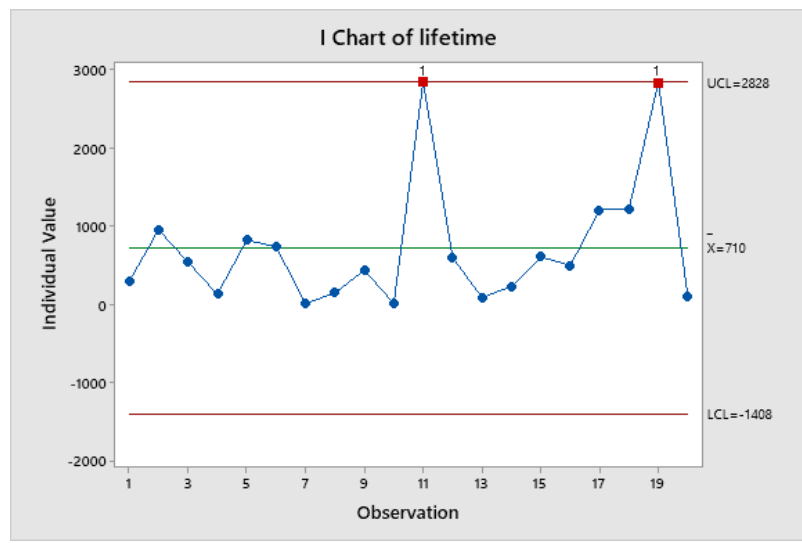

Figure 9. Individual chart of Montgomery data. Minitab 19 used.
Montgomery, copying from Nelson, decided to transform the data from the Exponential distribution to the Weibull distribution and considered the transformed data as Normally distributed; so he used the usual formulae for the control limits (Figure 10):

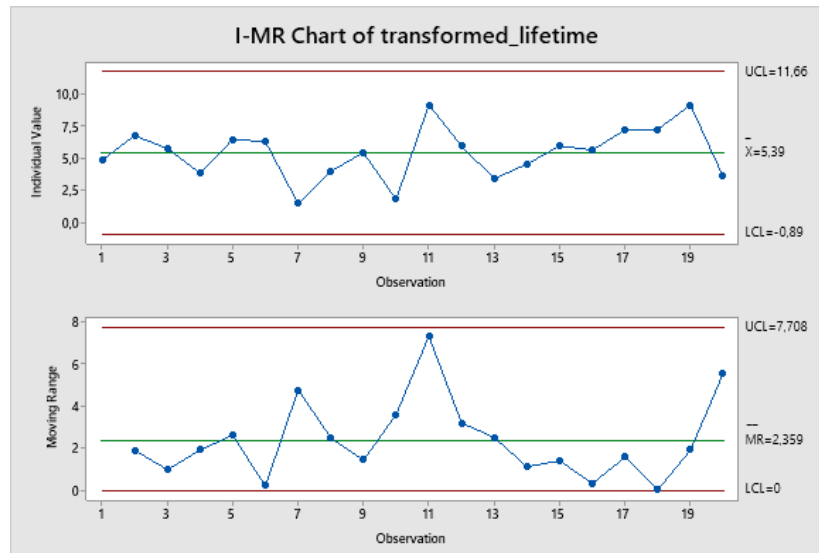

Figure 10. Individual and Moving Range chart of "transformed" Montgomery data. Minitab 19 used (F. Galetto).

From Figure 10, Professor Montgomery decided that the Process was IC: actually, with the right method, the Process is OOC.

The same type of error is provided by MINITAB, with its T Charts. Another wrong method, publicized by E. Santiago, J. Smith in their wrong paper ${ }^{[114]}$.

Quality Engineering has "Peer Reviewed" papers and is a trusted Journal, not asking any fee to the authors, but publishes wrong papers...

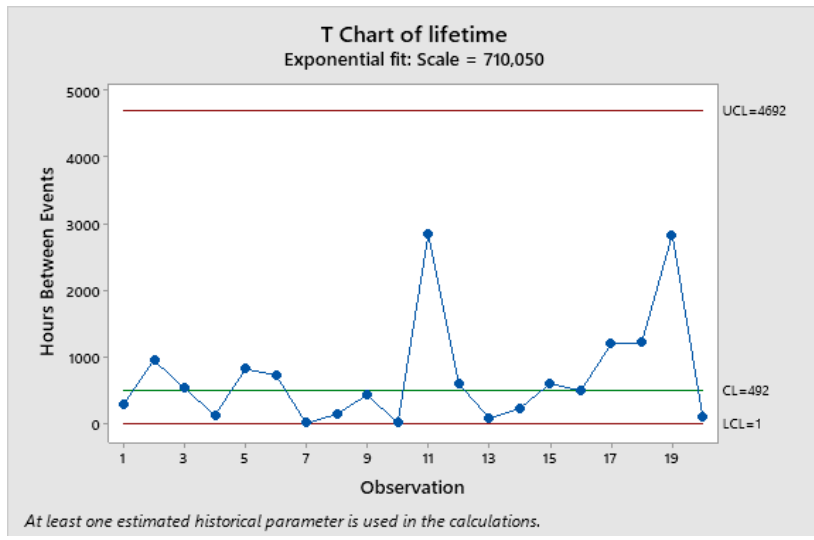

Figure 11. Montgomery data. (T Chart by Minitab 19 used by F. Galetto) (same with Minitab 20, 16 December 2020).

Notice the qualifications of the authors.

E. Santiago, a technical training specialist and J. Smith, a statistician, are working at Minitab; both have good qualifications. Their paper was Peer Reviewed and ended with thanks to $W$. H. Woodall (for his help to improve the paper) and two anonymous referees (for their comments to 
improve the paper).

So this is the situation we are confronted with: qualified authors, one qualified reader (Dr. Woodall), qualified Referees and several other qualified readers.

None of them found that the paper has WRONG Formulae for the Control Limits!

These "wrong formulae are used by Minitab", as well!

The authors did not pay any APC (Article Processing Charge) to a "Predatory Journal" ...

Their paper is NO good!

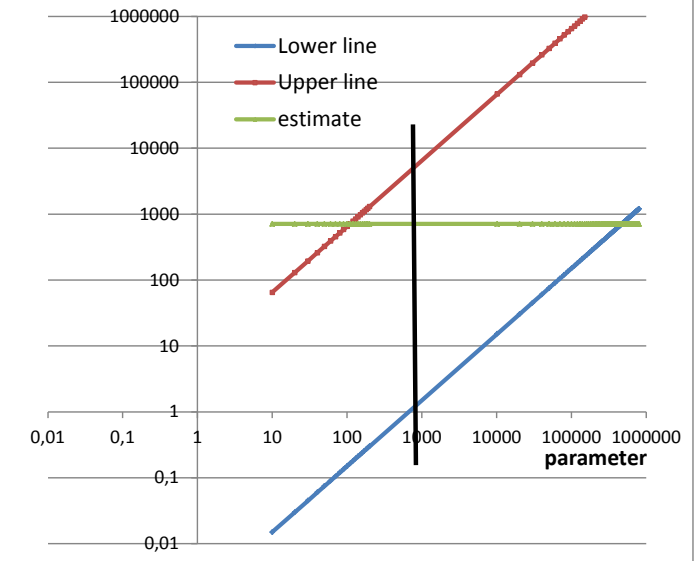

Figure 12. Control Limits for the T Chart of Montgomery data, using RIT(F. Galetto).
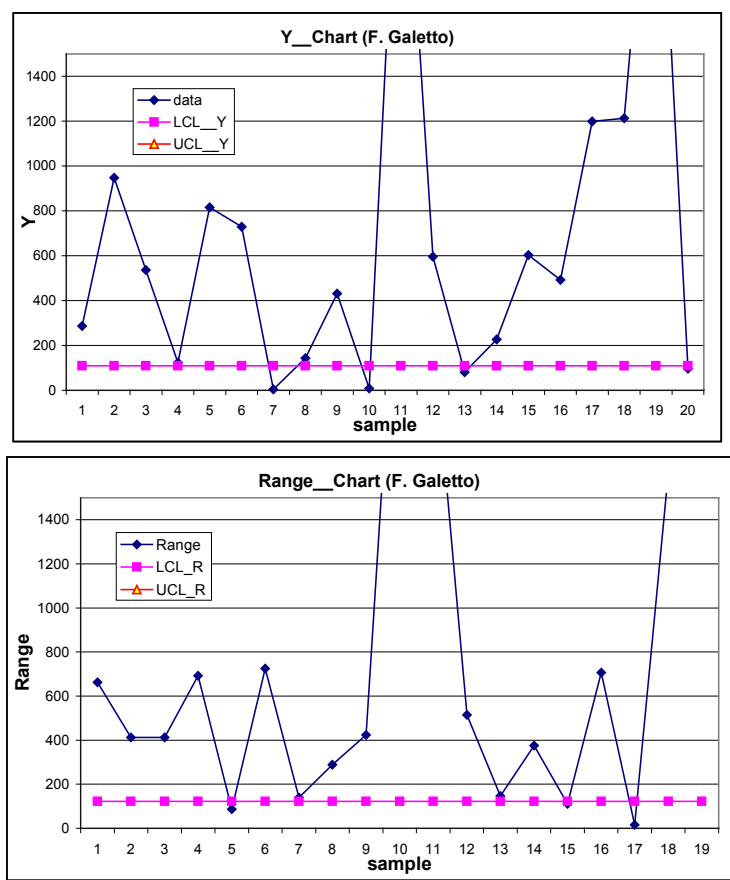

Figure 13. Control Limits for the T Charts of Montgomery data and for the Ranges, using RIT(F. Galetto).

Using RIT ${ }^{[102-108]}$, anybody can find the "Process is Out Of Control" (Figures 12-13). The green horizontal line (in Figure 12 with logarithmic scales) intercepts the ordinate axis at the Mean of the data; the abscissas of the points of interceptions of the green horizontal line with the Upper and Lower lines are the Lower and Upper Control Limits of the T Chart.

Moreover the Ranges are "Out Of Control": they too are Exponentially distributed (see Figure 13)! ${ }^{[104,105]}$

In the Figure 13 the points (data) below the Lower Control Limit indicate "Process Out Of Control"!

Other reputed authors Kittlitz, Schilling, Nelson, Woodall, Xie, Goh, Kuralmani, Ranjan, Zhang, published in other trusted Journals and made the same errors ${ }^{[115-123]}$. Journal of Quality Technology, Kluwer Academic Publisher, Reliability Engineering \& System Safety, chapter 16 in the book Engineering Statistics (Pham Editor): Springer-Verlag, International Journal of Production Research, IIE Transactions, Computers and Industrial Engineering.

Reader, what is your honest conclusion?

\section{Estimation from Incomplete Samples}

Often, in the Reliability Test (and field), we have "INCOMPLETE samples" of data: we have time to failure data and data (named suspensions) related to NON_failed items.

RIT provides the solution for estimating the MTTF, the failure rate, the Reliability, ...

This problem of estimation from "INCOMPLETE samples" is GENERALLY not considered by statisticians and is not dealt in the Statistics books; they consider only the "COMPLETE samples" and they do not say that their formulae hold only for those type of samples (in the reliability field, all the data refer to failures).

Unfortunately, EVEN THOUGH they teach Reliability, many and many professors are not really experts in the Reliability Theory.

See the following exam exercise that has been given several times, by the author, to his student: 3 incompetent [Italian] authors wrote a reliability book written from which the case was taken: the reliability data (time to failure) of the test are assumed NORMALLY distributed!!!! [Macchina di prova stands for item on test, Tempo al guasto (ore) stands for Time To Failure (hours)]. 40 TTF were collected (sample complete: all the items failed). The authors (professors) say (in Italian)

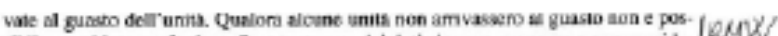

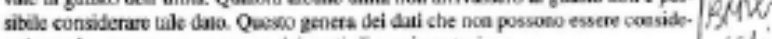
frati ma che cominque generano del ocsti di sperimentzrione.

[translation: If some of items do not fail it is not possible to use that datum. This generates data that cannot be considered but that in any case generate experimental costs] The THREE SUPER incompetent professors are highly rated in the so called «<scientific communin $\gg \gg>$ !!!!!! 
Here is the Exam Exercise:

====Esercizio $n .12$ MOLTO ISTRUTTIVO relativo ad un libro sull'Affidabilità di 3 BMWisti. Analyse the data of reliability tests ...: THREE incompetent professors say, proving their whole IGNORANCE (they say that if some items do not fail by the end of the test the "suspended items" can NOT be considered in the computations)

YOU suppose that the test is truncated at $400 \mathrm{~h}$ : estimate the MTTF, WITHOUT neglecting the "suspended items". (the data are time to failure: data $>400$ must be considered as non failed at 400) BMWisti means ....

Misura e analisi dell'affidabilità 79

\begin{tabular}{cccc} 
Tabella 5.1 Esempio di dati rappresentabili con una distribuzione normale. \\
\hline $\begin{array}{c}\text { Macchina } \\
\text { di prova }\end{array}$ & $\begin{array}{c}\text { Tempo } \\
\text { al guasto (ore) }\end{array}$ & $\begin{array}{c}\text { Macchina } \\
\text { di prova }\end{array}$ & $\begin{array}{c}\text { Tempo } \\
\text { al guasto (ore) }\end{array}$ \\
\hline 1 & 420 & 12 & 480 \\
2 & 360 & 13 & 340 \\
3 & 340 & 14 & 300 \\
4 & 320 & 15 & 400 \\
5 & 240 & 16 & 440 \\
6 & 380 & 17 & 360 \\
7 & 300 & 18 & 340 \\
8 & 200 & 19 & 500 \\
9 & 300 & 20 & 220 \\
10 & 340 & 21 & 300 \\
11 & 280 & 22 & 380 \\
\hline
\end{tabular}

$$
\mu=343 \text { ore }
$$$$
\sigma=77 \text { ore }
$$

Si noti come nelle prove sperimentali si sono considerate solo quelle che siano arrivate al guasto dell'unità. Qualora alcune unità non arrivassero al guasto non è posvate al guasto dell'unità. Qualora alcune unità non arrivassero al guasto non è pos-
sibile considerare tale dato. Questo genera dei dati che non possono essere conside-

Poor students cheated and deceived by the professors they met and to be met....! YOU are guilty, because you do not use your brain! "Can you be better than the great professorSSSSSSS?"

Excerpt 3. (An exam exercise given by Fausto Galetto to his students)

To pass the test the students, obviously, could not be as stupid as those professors! One of the 3 authors was very good (???); you could meet him at the SIX SIGMA lessons: Director of the Master on $6 \sigma$ ! He has excellent qualification: Taguchi Award Winner, MBB, author of 9 books,.. In spite of that, he teaches wrong ideas.

Is this professor able to solve the cases in the sections 4 and 5?

Will all those incompetent professors consider their responsibility to teach scientifically and to satisfy the learning needs of students and of the whole society. See (Figure $1), \ldots$

There is NO Quality in teaching wrong ideas and methods! Teaching has to be scientific (Figure 1).

If those three incompetent profs. had studied the Theory they should have found the books about RIT and then ...

\section{SPQR and OAJ versus NOAJ}

We proved, and now it should be very clear, that NOAP have the same problems as have OAP: the authors have the primary responsibility of their papers quality; if the Referees are not really competent they are not able to see the errors ${ }^{[9-131]}$.

The fee, asked by OAP, to authors does not influence their papers quality if they are truly competent. The "reputation of journals and magazines" [from 85 to 95,126$]$ does not assure the quality of the paper published.

See the following Inspection Plan with wrong detection

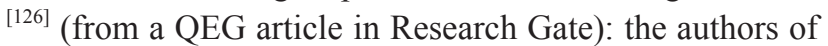
the paper write about the defectiveness of items checked in an Inspection Plan: the defectiveness (that obviously is varying because is the realisation of a random variable) has the mean value $\mathrm{E}(\mathrm{X})=\mathrm{p} \beta$, caused by the wrong detection, where

1. " $p$ is the probability that a product is REALLY defective"

2. " $\alpha$ is the probability that a product, REALLY NON defective, is WRONGLY detected as defective"

3 . " $\beta$ is the probability that a product, REALLY defective, is WRONGLY detected as NON_defective"

In F. Galetto's opinion, $\mathrm{E}(\mathrm{X})$ cannot be the above formula.

He asked that to the expert scholars in RG: "What do the Research Gate experts think? "NO answer!

Those experts have been unable to use Logic SPQR to understand if the "proposed method" is to be appied or it must be refused.

Now it is evident the title of this paper: Quality of papers stems from authors and Quality of teaching stems from professors.

The following case is very illuminating: the origin of the Disquality Vicious Circle "Presumption-Ignorance-Presumption- Ignorance" (Figure 15, published on 2008 and related to Figure 14).

Some professors of various university organised (2001) a Design Of Experiment Post-Graduate course. F. Galetto decided to attend the course (as an "intelligent pupil") to see what the "Montgomery fans" would teach (also a QEG professor was teaching there!). The experience was quite negative :the professors were incapable to teach "scientifically" the subject.

After the author invented the Disquality Vicious Circle" and published the paper ${ }^{[82]}$ (with G. Pistone, M. P. Rogantin): during the course the two co-authors did not believed what you can find in the books ${ }^{[52,67]}$. See also ${ }^{[109-111]}$.

By presenting several papers in international Conferences ${ }^{[34-101,111]}$, and by writing several books ${ }^{[102-110]}$, 
the author have been trying to diffuse the idea that decision-making has to be based on Scientific Methods.

See also ${ }^{[124,125,-180]}$, many documents (cases of wrong papers) in Research Gate and in Academia.edu.

The following case is very illuminating, as well: when the "students were defending their final thesis" (to get their degree in Engineering), Fausto Galetto used to open the written thesis at a "random" page and to ask the "graduating guy"what he meant with some statements found there. $90 \%-98 \%$ of the students did not know how to provide any answer to the questions: moreover, $50 \%$ $60 \%$ said "I copied it from the web!" That was not the biggest problem: it always was astonishing to see that the (Professors) Referees (as well) of the theses did not know the matter/answer themselves! These are hard facts, not opinions; the same facts were found by Deming and GellMann..., and Einstein...

\section{Conclusions (using SPQR)}

We present here some few ideas about Quality. A longer set of them can be found in ${ }^{[112]}$.

Professors, Scholars, Researchers and Managers have to stay with STEM (Science, Technology, Engineering and Mathematics), i.e. LOGIC to prevent and avoid DISquality! (see the Quality Tetralogy ${ }^{[104-112]}$ )

There are many methods misleading (e.g. Taguchi Methods, Bayes Methods, ...); so the previous guys must be EDUCATED ON QUALITY.

They should always remember Deming's statements ${ }^{[3]}$ at pages 19, 129, 131; see Figure 1, as well.

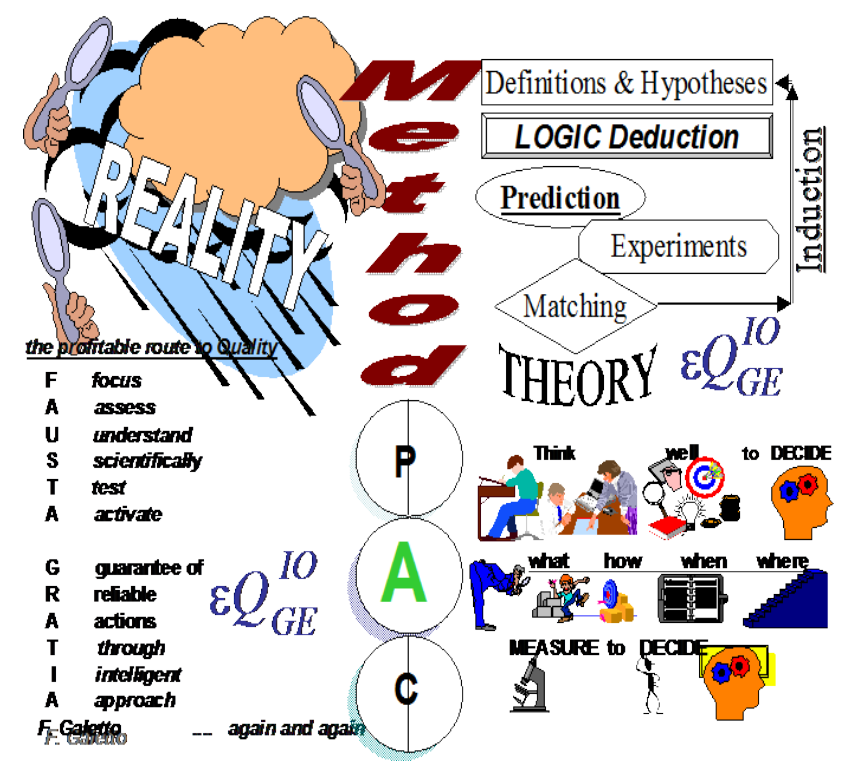

Figure 14. FAUSTA GRATIA for Quality in order to avoid the Disquality.

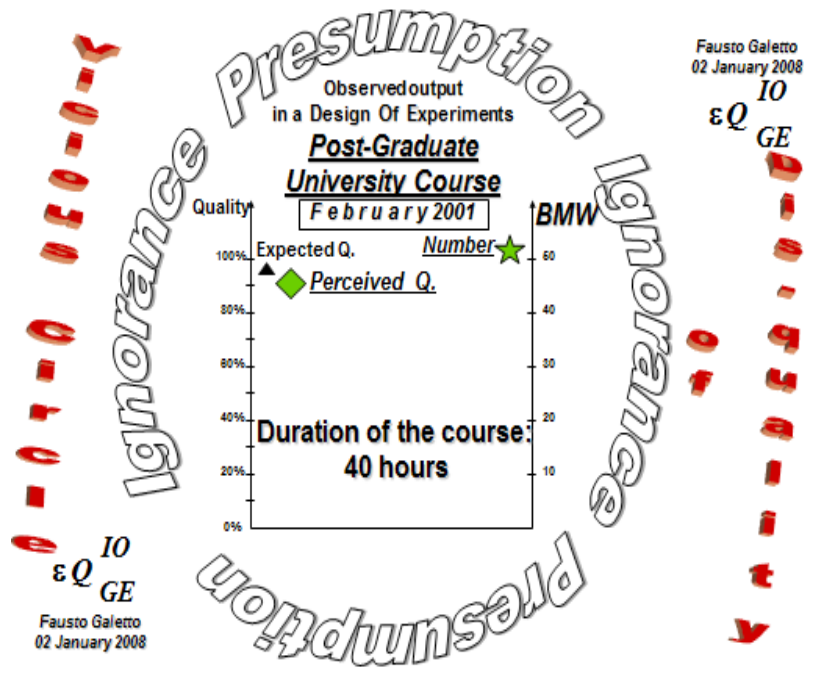

Figure 15. The Disquality Vicious Circle.

The previous guys should think that there are two fundamental principles to use fully the thinking ability of people:

F1 Reality does exist in spite of human beings' willingness and ability to recognize it.

F2 Variation is in everything and everywhere, all the time.

From F2 anybody can derive that "“variation" is NOT the enemy of Quality», as several "intelligent (are they ????)" people [in the 6 Sigma field] say! Variation is in every phenomenon and is important: if life was developing for millions of years that was merit of the VARIATION! The sons of relatives have more problems than the sons of NON_relatives... Biodiversity is the foundation of ecosystems to which human well-being is intimately linked.

These hard facts have been seen by the author during his long experience in the Quality Field, as manager, professor, consultant and scholar.

I. Newton (great scientist) said "If I have seen farther than others, it is because I have stood on the shoulders of giants"; he used SPQR, without having invented it; before him Galileo Galilei, another great scientist, used it; after him, A. Einstein did the same.

Knowledge accumulation is a characteristic of the process of Science; the discoveries of one people generation serve for the future ones. This is true for any discipline (e.g. Logic, Mathematics, Physics, Probability, Statistics, Medicine, Economics, Reliability...): any building needs sound foundations.

Knowledge and the Knowledge-Making process must have Quality obtained through Quality Tools and Methods, as depicted in the Figures 14, 15, 16 Quality Tools and Quality Methods to avoid the Disquality. 


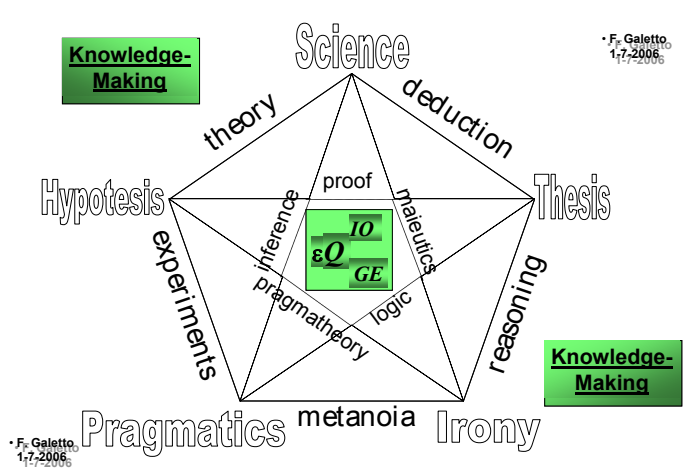

Figure 16. Quality Tools and Quality Methods to avoid the Disquality.

Notice that Quality of papers or books does not depend on their number of citations and a paper cannot be considered "successful" when receiving more citations than those made, as suggested by QEG [an idea of Kosmulski (2011)]; QEG, disregarding completely Figures 14, 15, 16, decid$\mathrm{ed}^{[132]}$ to propose to classify a publication as "successful" when it receives more citations than a specific comparison term $(C T)$. They defined the success-index as the number of successful papers, among a group of publications examined, such as those associated to a scientist or a journal. See ${ }^{[126-131]}$ and think if a scholar can be like that...

Paper ${ }^{[97]}$ shows the many drawbacks of this QEG attitude.

Using the SPQR Principle and taking into account that only the Scientific Attitude provides good results, any sensible Scholar can see the drawbacks both of OAP and NOAP: the bad quality of the paper published does not depend on the fee, asked by the OAP), but on the very low quality of the authors and of the Peer Reviewers; the same happens for "well reputed magazines and journals" (NOAP).

Remember Deming, Juran, Gell-Mann, Shewhart ${ }^{[3-8]}$ and A. Einstein

What we said can be extended to book publishers e.g. Wiley \& Sons ${ }^{[9-13]}$ and others ${ }^{[133-147]}$ versus ${ }^{[102-110]}$.

We think that all the relevant concept about Quality are embodied in the following two figures (17 and 18).

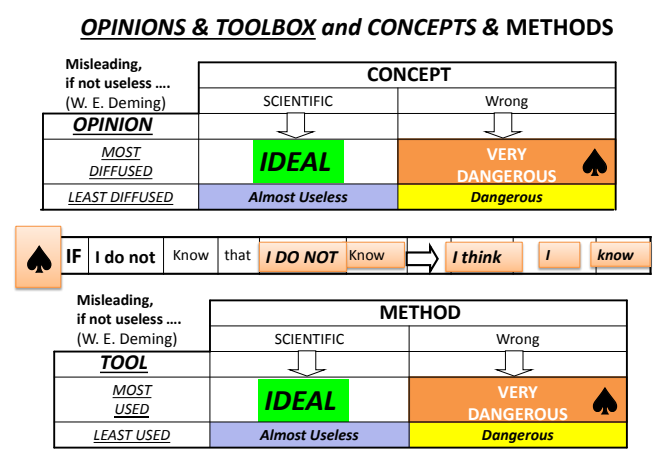

Figure 17. Opinions\&Tool-box and Concepts\&Methods

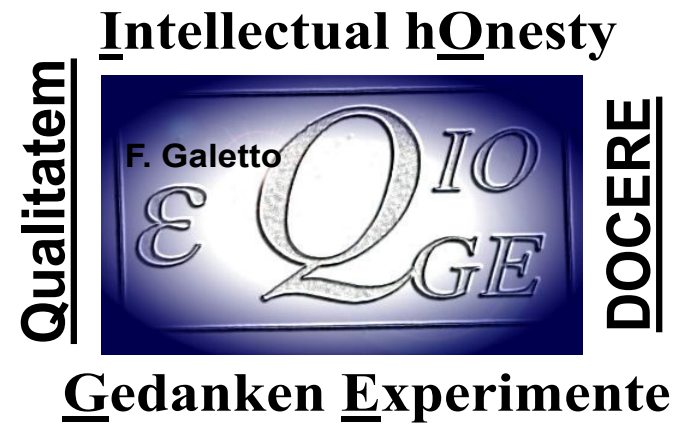

Figure 18. The epsilonQuality ( $\varepsilon Q)$ to Teach Quality (Qualitatem Docere) with Intellectual hOnesty (IO) and Gedanken Experimente (GE)

$\varepsilon Q$ conveys the idea that Quality must be considered in every place, every activity and every time with IO and GE (ideas of Galilei and Einstein). Quality is very much related to sound concepts and Methods.

Every scholar must change his mind ( $\mu \varepsilon \tau \alpha^{\prime} v o 1 \alpha$, metanoia is a word of Deming) to devise good methods ( $\mu \varepsilon^{\prime} \vartheta_{0} \delta \circ \varsigma$ ) as in the following permanent sequence

$$
\begin{aligned}
& \Rightarrow \mu \varepsilon \tau \alpha^{\prime} \text { vol } \Rightarrow \mu \varepsilon^{\prime} \vartheta_{\text {o } \delta \text { o } \varsigma \Rightarrow \mu \varepsilon \tau \alpha^{\prime} \text { voเ } \alpha \Rightarrow} \Rightarrow \\
& \Rightarrow \mu \varepsilon^{\prime} \vartheta_{\mathrm{o} \delta \mathrm{o} \varsigma} \Rightarrow \mu \varepsilon \tau \alpha^{\prime} \text { vol } \alpha \Rightarrow \mu \varepsilon^{\prime} \vartheta_{\mathrm{o} \delta \mathrm{o} \varsigma} \Rightarrow
\end{aligned}
$$

Why professors do not follow it?

\section{References}

[1] scienceblogs.com/../2012/../nice-try-science-publishing-group

[2] www.sabhlokcity.com/./more-on-the-science-publishing-group

[3] Deming W. E., 1986, Out of the Crisis, Cambridge University Press.

[4] Deming W. E., 1997, The new economics for industry, government, education, Cambridge University Press.

[5] Juran, J., 1988, Quality Control Handbook, 4th ed, McGraw-Hill, New York.

[6] M. Gell-Mann., 1994, The Quark and the Jaguar: Adventures in the Simple and the Complex, W. Freeman and Company, N. Y.

[7] Shewhart W. A., 1931, Economic Control of Quality of Manufactured Products, D. Van Nostrand Company.

[8] Shewhart W. A., 1936, Statistical Method from the Viewpoint of Quality Control, Graduate School, Washington.

[9] Montgomery D. C., 1996, Introduction to Statistical Quality Control, Wiley \& Sons (wrong definition of 
the term "Quality", and many other drawbacks in wrong applications).

[10] Montgomery D. C., 2009, $6^{\text {th }}$ edition, Introduction to Statistical Quality Control, Wiley \& Sons (wrong).

[11] Montgomery D. C., 2011, $5^{\text {th }}$ edition, Applied Statistics And Probability For Engineers, Wiley \& Sons.

[12] Montgomery D. C., 2013, $8^{\text {th }}$ edition, Design and Analysis of Experiments, Wiley \& Sons.

[13] Montgomery D. C., editions after 2009 are worse, Introduction to Statistical Quality Control, Wiley \& Sons (wrong definition of the term "Quality", and many other drawbacks in wrong applications).

[14] Cascini E., Sei Sigma per docenti in 14 capitoli, RCE Multimedia 2009.

[15] Arcidiacono G., et al. Governare i processi per governare l'impresa - Lean Six Sigma, Springer 2014.

[16] Citti P., La metodologia sei sigma nei servizi, Firenze University Press 2006.

[17] Pyzdek T., The Six Sigma Handbook A Complete Guide For Green Belts, Black Belts, And Managers At All Levels, McGraw-Hill 2003.

[18] Munro R., et al., The Certified Six Sigma Green Belt Handbook, American Society for Quality 2015.

[19] Pande P., et al., The Six Sigma Way_How GE, Motorola, and Other Top Companies are Honing their performance, McGraw-Hill.

[20] Brue G., Six Sigma for Managers, McGraw-Hill 2005.

[21] Eckes G., Six Sigma for Everyone- (2003) Managers, Wiley 2003.

[22] Craig G. et al., Six Sigma for Dummies, Wiley 2012.

[23] Allen T., Introduction to Engineering Statistics and Six Sigma, Springer 2006.

[24] PARK S. (1996), Robust Design and Analysis for Quality Engineering, Chapman \& Hall, London.

[25] F. Kutsanedzie, S. Achio, E. Ameko, Basic concepts and applications of experimental design, Science Publishing Group 2015, ISBN:978-1-940366-500.

[26] Taguchi G., "Product quality evaluation and tolerancing", 30th EOQC Conference, Stockholm 1986.

[27] Taguchi G., System of Experimental Design, vol.1, ASI (American Supplier Institute) and Unipub Kraus International Publications.

[28] Taguchi G., System of Experimental Design, vol.2, ASI and Unipub Kraus International Publications.

[29] Taguchi G., Introduction to quality engineering, Asian Productivity Organization, 1988.

[30] Taguchi G., Yu-In Wu, Introduction to off-line quality control, Central Japan Quality Control Association, 1979.

[31] Taguchi S., Byrne D., 1986 The Taguchi Approach to Parameter Design, Best Technical Paper (!?), Ameri- can Society for Quality Control.

[32] F. Franceschini, M. Galetto, D. Maisano, L. Mastrogiacomo, B. Pralio, Distributed Large-Scale Dimensional Metrology, New Insights, Springer-Verlag London Limited 2011.

[33] Franceschini F, Maisano D, Mastrogiacomo L, Pralio B (2010) Ultrasound transducers for largescale metrology: a performance analysis for their use by the MScMS. IEEE Trans Instrum Meas 59 (1):110-121.

[34] F. Galetto, Nuovi sviluppi nel calcolo dei parametri affidabilistici dei sistemi, LXXIII Riunione annuale AEI, Torino, 1972.

[35] F. Galetto, Numero dei guasti di un sistema e determinazione di un modello reale atto a rappresentarlo, VIII congr. AICQ, Napoli, 1973.

[36] F. Galetto, Integrazione Numerica di Equazioni Integrali di Volterra, Facoltà di Matematica, Bologna, 1973.

[37] F. Galetto, Pitfalls of Bayes Methods, Internat. conf. on Reliability/ Diagnostics, Torino, 1986.

[38] F. Galetto, CLARA (Cost and Life Appraisal via Reliability Analysis), $30^{\text {th }}$ EOQC Conference, Stoccolma, 1986.

[39] F. Galetto, SARA (System Availability and Reliability Analysis), Annual Reliability Symposium, Philadelphia, 1977.

[40] F. Galetto, CLAUDIA (Cost and Life Analysis via Up and Down time Integral Approach), XXI EOQC Conf., Varna, 1977.

[41] GALETTO F. (1978), An application of experimental design in the Automotive field, SIA Congress.

[42] F. Galetto, NORA (a New Outlook on Reliability of Automobiles), XXIII EOQC Conf., Budapest, 1979.

[43] F. Galetto, New results in reliability analysis, $2^{\text {nd }}$ Int. Conf. on Reliability/ Maintainab., Perros- Guirec, 1980.

[44] F. Galetto, (1984) Assessment of Product Reliability, World Quality Congress '84, Brighton.

[45] F. Galetto, (1986) Quality/Reliability: How to get results, EOQC (Automotive Section), Madrid.

[46] F. Galetto, Are Bayes Methods really better ?, IASTED Int. Conf. on Quality/ Reliability, Paris, 1987.

[47] F. Galetto, (1987) Quality and Reliability, the Iveco way, Mgt Dev. Review by MCE, Brussels.

[48] F. Galetto, (1988) Quality and reliability. A must for industry, ISATA, Montecarlo.

[49] F. Galetto, Comment on: 'New Practical Bayes Estimators for the 2-parameters Weibull distribution, IEEE Transactions on Reliability vol.37, 1988.

[50] F. Galetto, (1989) Quality of methods for quality is important, EOQC Conference, Vienna.

[51] F. Galetto, (1990) Basic and managerial concerns on 
Taguchi Methods, ISATA, Florence.

[52] F. Galetto, Qualità. Alcuni metodi statistici da Manager, CUSL, 1995.

[53] F. Galetto, Quality: Management Commitment is not enough, ISATA, Vienna, 1990.

[54] GALETTO F., LEVI R. (1993) Planned Experiments: key factors for product Quality, 3rd AMST 93, Udine.

[55] F. Galetto, (1993) DOE. Importanti idee sulla Qualità per i manager, DEINDE, Torino.

[56] F. Galetto, (1993) Which kind of Quality? Of products, of processes, of Management? $1^{\text {st }}$ AITEM, Ancona.

[57] Galetto, F., Managerial Issues for Design of Experiments, $4^{\text {th }}$ AMST 96, Udine, 1996.

[58] Galetto, F., We need Quality of Managers, Quality 97, $6^{\text {th }}$ Intern. Conf., Ostrava, Czeh Republic, 1997.

[59] Galetto, F., Quality Education on Quality for Future Managers, $1^{\text {st }}$ Conference on TQM for HEI (Higher Education Institutions), Tolone, 1998.

[60] Galetto, F., GIQA the Golden Integral Quality Approach: from Management of Quality to Quality of Management, Total Quality Management (TQM), Vol. 10, No. 1, 1999.

[61] Galetto, F., Quality Education and Total Quality Management, $2^{\text {nd }}$ Conf. on TQM for HEI, Verona, 1999.

[62] Galetto, F., Quality Methods for Design of Experiments, $5^{\text {th }}$ AMST 99, Udine, 1999.

[63] Galetto, F., Quality Function Deployment, Some Managerial Concerns, AITEM99, Brescia, 1999.

[64] GALETTO F., GENTILI E. (1999), The need of Quality Methods used for Quality CAPE '99, Durham, UK.

[65] GALETTO F., GENTILI E. (1999), Quality of the Quality Methods, AITEM 99 Conference, Brescia.

[66] GALETTO F., GENTILI E. (2000), In search of Quality in QFD and Taguchi methods, CAPE.

[67] GALETTO F. (2000) Qualità. Alcuni metodi statistici da Manager, CLUT, Torino.

[68] Galetto, F., Quality Education for Professors teaching Quality to Future Managers, $3^{\text {rd }}$ Conf. on TQM for HEI, Derby, UK, 2000.

[69] Galetto, F., Statistical Thinking, Customer Satisfaction, Qualità del Servizio e Formazione Universitaria, Conv. SIS, Firenze, 2000.

[70] Galetto, F., Quality, Bayes Methods and Control Charts, $2^{\text {nd }}$ ICME 2000 Conference, Capri, 2000.

[71] Galetto, F., Reliability Integral Theory applied to "two machines lines" with failures, $2^{\text {nd }}$ ICME 2000 Conference, Capri, 2000.

[72] Galetto, F., RELIABILITY PREDICTION DURING
DEVELOPMENT, ATA conf., Firenze, 2000.

[73] Galetto, F., Looking for Quality in "quality books", $4^{\text {th }}$ Conf. on TQM for HEI, Mons, Belgium, 2001.

[74] Galetto, F., Quality and Control Charts: Managerial assessment during Product Development and Production Process, AT\&T (Society of Automotive Engineers), Barcelona, 2001.

[75] Galetto, F., Quality QFD and control charts: a managerial assessment during the product development process, Congresso ATA, Firenze, 2001.

[76] Galetto, F., Business excellence Quality and Control Charts, $7^{\text {th }}$ TQM Conf., Verona, 2002.

[77] Galetto, F., Fuzzy Logic and Control Charts, $3^{\text {rd }}$ ICME 2002 Conference, Ischia, 2002.

[78] Galetto, F., Quality education on Quality for future managers, 5th World Congr. on Engineering Education of NOT, Varsavia, 2002.

[79] Galetto, F., Analysis of "new" control charts for Quality assessment, $5^{\text {th }}$ Conf. on TQM for HEI, Lisbon, Portugal, 2002.

[80] Galetto, F., Quality decisions and ISO 9000:2000 Principles, 6th AMST 99, Udine, 2002.

[81] Galetto, F., Quality and "quality magazines", $6^{\text {th }}$ Conf. on TQM for HEI, Oviedo, Spain, 2003.

[82] Galetto F., G. Pistone, M. P. Rogantin, Confounding revisited with commutative computational algebra, Journal of statistical planning and inference,, 2003.

[83] Galetto, F., "Six Sigma Approach" and Testing, ICEM12-12 ${ }^{\text {th }}$ Intern. Conf. on Experimental Mechanics, Bari Politecnico, 2004.

[84] Galetto, F., Reliability analysis in product development, AMST 2005, Udine, 2005.

[85] Galetto, F., Statistics for Quality and "quality magazines", $5^{\text {th }}$ ENBIS, Newcastle, 2005.

[86] Galetto, F., Service Quality: Fuzzy Logic and Yager Method; a scientific analysis, IFIP TC 7, Politecnico di Torino, 2005.

[87] Galetto, F., Quality and "Statistics Packages", $8^{\text {th }}$ Conf. on TQM for HEI, Palermo, 2005.

[88] Galetto, F., Quality Education and "quality papers", IPSI 2006, Marbella, 2006.

[89] Galetto, F., Fuzzy Logic and Quality Control: a scientific analysis, IPSI 2006, Amalfi, 2006.

[90] Galetto, F., Quality Education versus "Peer Review", IPSI 2006, Montenegro, 2006.

[91] Galetto, F., Does "Peer Review" assure Quality of papers and Education?, $8^{\text {th }}$ Conf. on TQM for HEI, Paisley, Scotland, 2006.

[92] Galetto, F., Quality Education versus "Peer Review", IPSI 2006, Montenegro, 2006.

[93] Galetto, F., A must: Quality of teaching, IPSI 2006, Portofino, 2006. 
[94] Galetto, F., The Pentalogy, VIPSI, Belgrado, 2009.

[95] Galetto, F., The Pentalogy Beyond, $9^{\text {th }}$ Conf. on TQM for HEI, Verona, 2010.

[96] Galetto, F., Six Sigma: help or hoax for Quality?, $11^{\text {th }}$ Conf. on TQM for HEI, Israel, 2012.

[97] Galetto, F., Bibliometrics: Help or Hoax for Quality?, UJER 2(4), DOI: 10.13189/ujer.2014.020404, 2014.

[98] Galetto, F., Riemann Hypothesis Proved, Academia Arena 6(12):19-22, ISSN 1553-992X, 2014.

[99] Galetto, F., Hope for the Future: Overcoming the DEEP Ignorance on the CI (Confidence Intervals) and on the DOE (Design of Experiments, Science J. Applied Mathematics and Statistics. Vol. 3, No. 3, pp. 70-95,

DOI: 10.11648/j.sjams.20150303.12, 2015.

[100]Galetto, F., Management Versus Science: Peer-Reviewers do not Know the Subject They Have to Analyse, Journal of Investment and Management. Vol. 4, No. 6, pp. 319-329,

DOI: 10.11648/j.jim.20150406.15, 2015.

[101]Galetto, F., The first step to Science Innovation: Down to the Basics., Journal of Investment and Management. Vol. 4, No. 6, pp. 319-329,

DOI: 10.11648/j.jim.20150406.15, 2015.

[102]Galetto, F., AFFIDABILITÀ vol. 1 Teoria e Metodi di calcolo, CLEUP editore, Padova, 81, 84, 87, 94.

[103]Galetto, F., AFFIDABILITÀ vol. 2 Prove di affidabilità: distribuzione incognita, distribuzione esponenziale, CLEUP editore, Padova, 82, 85, 94.

[104]Galetto, F., Qualità. Alcuni metodi statistici da Manager, CUSL, 1995/7/9.

[105]Galetto, F., Gestione Manageriale della Affidabilità. CLUT, Torino.

[106]Galetto, F., Manutenzione e Affidabilità. CLUT, Torino.

[107]Galetto, F., 2016, Reliability and Maintenance, Scientific Methods, Practical Approach, Vol-1, www. morebooks.de.

[108]Galetto, F., 2016, Reliability and Maintenance, Scientific Methods, Practical Approach, Vol-2, www. morebooks.de.

[109]Galetto, F., 2016, Design Of Experiments and Decisions, Scientific Methods, Practscal Approach, www. morebooks.de.

[110]Galetto, F., 2017, The Six Sigma HOAX versus the versus the Golden Integral Quality Approach LEGACY, www.morebooks.de.

[111]Galetto, F., 2017, Six Sigma Hoax: The Way Professionals Deceive Science. Nuclear Science. Vol. 2, No. 3, 2017, pp. 59-81.

DOI: $10.11648 /$ j.ns.20170203.11
[112]Galetto, F., The SPQR (《Semper Paratus ad Qualitatem et Rationem 》) Principle in Action. Engineering and Applied Sciences. Vol. 2, No. 3, 2017, pp. 27-52.

DOI: $10.11648 /$ j.eas.20170203.11

[113]iSixSigma, https://www.isixsigma.com

[114]E. Santiago, J. Smith, Control charts based on the Exponential Distribution, Quality Engineering, 25:2, 85-96: https://www.tandfonline.com/doi/abs/10.1080 /08982112.2012.740646

[115]Kittlitz, R. G. (1999). Transforming the exponential for SPC applications. Journal of Quality Technology, 31:301-308.

[116]Schilling, E. G., Nelson, P. R. (1976). The effect of non-normality on the control limits of X charts. Journal of Quality Technology, 8:183-188.

[117]Woodall, W. H. (2006). The use of control charts in health-care and public health surveillance. Journal of Quality Technology, 38:89-104.

[118]Xie, M., Goh, T. N., Kuralmani, V. (2002). Statistical Models and Control Charts for High-Quality Processes. Boston, MA: Kluwer Academic Publisher.

[119]Xie, M., Goh, T. N., Ranjan, P. (2002). Some effective control chart procedures for reliability monitoring. Reliability Engineering \& System Safety, 77:143-150.

[120]Xie, M., (2006). Some Statistical Models for the Monitoring of High-Quality Processes. Boston, chapter 16 in the book Engineering Statistics (Pham Editor): Springer-Verlgag.

[121]Zhang, C. W., Xie, M., Goh, T. N. (2005). Economic design of exponential charts for time between events monitoring. International Journal of Production Research, 43:5019-5032.

[122]Zhang, C. W., Xie, M., Goh, T. N. (2006). Design of exponential control charts using a sequential sampling scheme. IIE Transactions, 38:1105-1116.

[123]Zhang, H. Y., Xie, M., Goh, T. N., Shamsuzzaman, M. (2011). Economic design of time-between-events control chart system. Computers and Industrial Engineering, 60(4):485-492.

[124]Galetto, F., Papers and Documents in the Academia. edu, 2015-2020.

[125]Galetto, F., Several Papers and Documents in the Research Gate Database, 2014 (the cases are in $\S 8$ a.-gg.).

[126]The QEG, Uncertainty evaluation in the prediction of defects and costs for quality inspection planning in low-volume productions, The International Journal of Advanced Manufacturing Technology (2020) 108:3793-3805

[127]The QEG (M. Galetto et al.), 'Defect Probability Es- 
timation for Hardness-Optimised Parts by Selective Laser Melting, the International Journal of Precision Engineering and Manufacturing (2020) 21:17391753

[128]F. Franceschini, Learning curves and p-charts for a preliminary estimation of asymptotic performances of a manufacturing process,Total Quality Management Journal (2002)

[129]The QEG (F. Franceschini et al.) Ordered Samples Control Charts for Ordinal Variables, Quality and Reliability Engineering International (2005)

[130]Yager A new methodology for ordinal multiobjective decision based on fuzzy sets. (1981)

[131]Minitab 19 and Minitab 20, "wrong T Carts"

[132]An informetric model for the success-index, Scientometrics, 2012

[133]«Birolini, A.: Reliability Engineering - Theory and Practice. Springer, Heidelberg, ISBN: 978-3-64214951-1»;

[134]«Beretta, S.: Affidabilità delle costruzioni meccaniche. Springer-Verlag 2009

[135]«Gertsbackh, I. Reliability Theory with Applications to Preventive Maintenance. Springer 2005

[136]«A. Regattieri, R. Manzini: Ingegneria di Manutenzione. Progetto Leonardo»

[137]«R. Manzini, A. Regattieri, H. Pham (Series Editor), E. Ferrari: Maintenance of Industrial Systems $[2+2$ professors (of 3 Universities)]. Springer Series in Reliability Engineering》

[138]«Reliability and Optimal Maintenance - Wang, H., Pham, H. (Author \& Series Editor), (Springer 2006)»

[139]«Pham, H. (one of the authors \& Editor of $\rightarrow$ ) Handbook of Engineering Statistics, (Springer 2006)»

[140]«E. Ferrari, A. Pareschi, A. Regattieri, A. Persona: Statistical Management and Modelling for Demand of Spare Parts. [in the Handbook of Engineering Statistics, (Springer 2006)] (Pham, H. (one of the authors $\&$ Editor of $\rightarrow \ldots)$...

[141]«Galar D. Sandborn P. Kumar U. Maintenance Costs and Life Cycle Cost Analysis»

[142]«M. Lazzaroni, L. Cristaldi, L. Peretto, P. Rinaldi, M. Catelani: Reliability Engineering [5 professors (of 4 Universities]. Springer 2003»

[143]«Montgomery D. C., 6th edition, Introduction to Statistical Quality Control, Wiley \& Sons 2009)

[144]«Nakagawa, T.: Maintenance Theory of Reliability. Springer (Springer Series in Reliability Engineering)»

[145]《Smith D. J.: Reliability, Maintainability and Risk $8^{\text {th }}$ Edition. Practical Methods for Engineers including Reliability Centred Maintenance and Safety-Related Systems»
[146]«Zio, E.: An introduction to the basics of Reliability and Risk Analysis. World Scientific Publishing 2007»;

[147]«Zio, E.: The Monte Carlo Simulation Method for System Reliability and Risk Analysis. Springer 2013 (Springer Series in Reliability Engineering, Pham, H. Editor of the ...)»;

[148]F. Galetto, Hope For The Future; overcoming the DEEP Ignorance on the Confidence Intervals_2014! QFG Quality MUST be loved, DISquality MUST be hated. Research Gate

[149]F. Galetto, Case n TWENTYTHREE; VERY BAD MISTAKES on Weibull data analysis by authors with High RG Scores and High Impact Points! QFG Quality MUST be loved, DISquality MUST be hated. Research Gate

[150]F. Galetto, Case n TWENTYTWO WRONG probability ideas on Insurance Mathematics and Economics ManEdit and Reviewers NOT reliable

[151]F. Galetto, ANOVA and Least Squares Estimation Some BASICS! Quality MUST be loved, DISquality MUST be hated. Research Gate

[152]F. Galetto, Case n TWENTYONE; A WRONGLY AWARDED wrong paper of on DOE, awarders are NOT reliable! Quality MUST be loved, DISquality MUST be hated. Research Gate

[153]F. Galetto, Quality Engineering vs "mathematicians" - QFG: case n TWENTY, QE wins!_MANY WRONGS do not make a right; Quality MUST be loved, DISquality MUST be hated. Research Gate

[154]F. Galetto, Case n NINETEEN, a WRONG Taguchi application AGAIN, REFEREES are NOT reliable! Quality MUST be loved, DISquality MUST be hated. Research Gate

[155]F. Galetto, Second Addendum to Case n EIGHTEEN, PEERS INCOMPETENT; Quality MUST be loved, DISquality MUST be hated for RG-2014 Research Gate

[156]F. Galetto, Addendum to Case n EIGHTEEN, PEERS INCOMPETENT; Quality MUST be loved, DISquality MUST be hated for RG-2014

[157]F. Galetto, Case n EIGHTEEN, PEERS INCOMPETENT; Quality MUST be loved, DISquality MUST be hated for RG-2014 Research Gate

[158]F. Galetto, Case n SIXTEEN; SECOND PART, other WRONG ideas of D.C. MONTGOMERY!!!!! Quality MUST be loved, DISquality MUST be hated. Research Gate

[159]F. Galetto, Case n FIFTHTEEN; the G-Method for MANOVA versus INCOMPETENT REFEREES !!!! (WRONG Taguchi applications) [ANOVA dealt in cases n NINE and ELEVEN], THIRD part Research 


\section{Gate}

[160]F. Galetto, Case n FOURTEEN; MANOVA of another WRONG Taguchi application [ANOVA dealt in case $n$ ELEVEN], REFEREES_INCOMPETENT!!!! SECOND part Research Gate

[161]F. Galetto, Case n THIRTEEN; some WRONG ideas of PROFESSOR D.C. MONTGOMERY!!!!! FIRST PART_Quality MUST be loved, DISquality MUST be hated. Research Gate

[162]F. Galetto, Quality Education on Quality and Design Of Experiments Research Gate

[163]F. Galetto, Case n TWELVE; MANOVA of a WRONG Taguchi application, REFEREES are NOT reliable! Quality MUST be loved, DISquality MUST be hated. Research Gate

[164]F. Galetto, Case n ELEVEN; another WRONG Taguchi application, REFEREES_INCOMPETENT!!!! FIRST part Quality MUST be loved, DISquality MUST be hated. Research Gate

[165]F. Galetto, Case n NINE; a WRONG Taguchi application, REFEREES are NOT reliable!!!! Quality MUST be loved, DISquality MUST be hated. Research Gate

[166]F. Galetto, Confidence Intervals (Classic Statistics) versus Credibility Intervals (Bayesian Statistics), first part Research Gate

[167]F. Galetto, Confidence Intervals (Classic Statistics) versus Credibility Intervals (Bayesian Statistics), second part Research Gate

[168]F. Galetto, Quality of Quality Methods is important Research Gate

[169]Galetto, F.,VIPSI_Belgrado2009-10_Pentalogy Research Gate

[170]Galetto, F.,THE CHALLENGE FOR THE FUTURE: QUALITY EDUCATION ON QUALITY FOR MANAGERS Research Gate

[171]Galetto, F.,QUALITY IN HIGHER EDUCATION COURSES Research Gate

[172]Galetto, F., Decisioni Aziendali e Metodi Statistici Research Gate

[173]Galetto, F., Quality and "quality magazines" Research Gate

[174]Galetto, F., Quality Education for Professors Teaching Quality to Future Managers Research Gate
[175]Galetto, F., QUALITY AND "STATISTICAL PACKAGES" Research Gate

[176]Galetto, F., Looking for Quality in "quality books" Research Gate

[177]Galetto, F., Does "Peer Review" assure Quality of papers and Education? Research Gate

[178]Galetto, F., IGNORANCE vs PRESUMPTUOUSNESS Research Gate

[179]Galetto, F., The Quality Manifesto_2014_01_07 Research Gate

[180]Galetto, F., Qualitatis_FAUSTA_GRATIA Research Gate

\section{Biography}

Fausto Galetto (born Italy 1942) received Electronics Engineering (1967) and Mathematics degrees (1973) from Bologna University; from 1992 to 2012 he was Professor of "Industrial Quality Management" at Politecnico of Turin; from 1998 to 2001 he was Chairman of the Working Committee "AICQ-Università" (AICQ) for Quality in Courses about Quality in Universities.

He wrote nine books and more than 200 papers on Reliability, Quality (Management, DOE, Applied Statistics, Testing, Process Control).

Reliability Engineer with General Electric, 2 years, be-

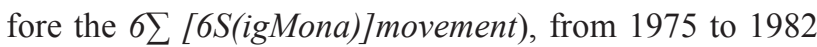
Reliability Manager (Fiat Auto, now FCA); Quality Dept. Director (comprising the Reliability, Production Quality Control, and After Sales Department) with Philco Italiana for 3 years. 1985-1990 Director of the Quality/Reliability Dept. at Iveco-Fiat, since 1990 Quality Management consultant. Lecturer with the Italian Organisation for Quality Control (AICQ) and with COREP(1980-2012).

Co-ordinator of: Reliability Working Group of CUNA (until 1989), Scientific and Technical Committee of QUALITAL (1989), Vice-Chairman of Automotive Sector of AICQ (1985-1990).

He left the SIS (Italian Statistical Society) and the AICQ (Italian Association for Quality) due to the ignorance and loss of commitment of their fellows and "Managers" about the Scientific Approach to Quality and to the related Quality Methods (Statistical and not...)

It seems he is one of the very few who take care of "Quality of Quality Methods used for making Quality". 